\title{
MONITORAMENTO DE VARIÁVEIS DE QUALIDADE DA ÁGUA NO CÓRREGO DAS LAGOAS NO MUNICÍPIO DE ILHA SOLTEIRA-SP
}

\section{Letícia de Oliveira Manoel}

\section{Sérgio Luís de Carvalho}

RESUMO: O homem vem ocupando de forma cada vez mais desordenada as bacias hidrográficas no planeta, através de atividades de desmatamentos, queimadas, práticas agrícolas perniciosas, atividades extrativistas agressivas, ocupações urbanas generalizadas gerando a impermeabilização dos solos, lançamento de esgotos industriais e domésticos nos rios e lagos. Enfim, todas essas atuações impactantes ao meio ambiente têm gerado uma deterioração da qualidade das águas naturais, com riscos de propagação de doenças de veiculação hídrica ao próprio ser humano. O presente trabalho, teve como objetivo avaliar a qualidade da água do Córrego das Lagoas, localizado no município de llha Solteira - SP. As amostragens foram realizadas durante o período de estiagem (maio a outubro) e chuvoso (novembro a abril), com periodicidade mensal, entre os meses de maio de 2012 a abril de 2013, em dois pontos de amostragem. As amostras foram analisadas quanto aos parâmetros físicos, químicos e microbiológicos, e os resultados das análises mostraram que o córrego das Lagoas apresenta alterações ligadas a fatores temporais e espaciais, com perda progressiva da qualidade das águas no período chuvoso, e diferenças na qualidade observada na nascente e na foz, onde os impactos na qualidade da água foram mais predominantes no Ponto 1 , que consiste na nascente do Córrego das Lagoas. Por sua vez, o monitoramento da qualidade das águas nestes locais contribui para o acompanhamento do estado ambiental do sistema e para identificar as pressões e os possíveis impactos.

Palavras-chave: Recursos hídricos. Variáveis físico-químicas. Sazonalidade. 


\section{INTRODUÇÃO}

O crescimento demográfico e o desenvolvimento socioeconômico são frequentemente acompanhados de aumentos na demanda por água, cuja quantidade e qualidade são de fundamental importância para a saúde e o desenvolvimento de qualquer comunidade (BUENO et al. 2005). A utilização do recurso hídrico para determinado propósito não deve prejudicar os diversos usos possíveis, entre os quais figuram as atividades de consumo humano, produção agropecuária, recreativas e a preservação da diversidade biológica. Em consequência, é necessário monitorar os recursos hídricos, a fim de disponibilizar informações que permitam propor medidas de manejo para manter os ambientes aquáticos com qualidade ecológica (STRIEDER et al. 2006).

Portanto, a implantação do monitoramento da qualidade e da disponibilidade da água torna-se fundamental no diagnóstico das condições do manancial, servindo assim de base para um melhor planejamento em relação ao uso adequado dos recursos hídricos e à elaboração de programas de recuperação de mananciais em estado de degradação.

Diante do exposto, este trabalho tem o objetivo de avaliar a qualidade da água por meio do monitoramento das variáveis físico-químicas e biológicas, no córrego das Lagoas no município de llha Solteira - SP, visando observar a variação sazonal desses parâmetros.

\section{MATERIAL E MÉTODOS}

\section{1. Área de estudo}

Este trabalho foi realizado no Córrego das Lagoas localizado na microbacia do Córrego Caçula no município de llha Solteira, região noroeste do Estado de São Paulo. Localizado na zona $22 \mathrm{~K}$, entre as coordenadas geográficas $20^{\circ} 24^{\prime} 44,8^{\prime \prime} \mathrm{S}$ e $51^{\circ} 17^{\prime} 06,5^{\prime \prime} \mathrm{O}$ e $20^{\circ} 30^{\prime} 16,4^{\prime \prime} \mathrm{S}$ e $51^{\circ} 22^{\prime} 16,2^{\prime \prime} \mathrm{O}$ Datum SIRGAS 2000 com altitude entre 290 a 370 metros acima do nível do mar. 
De acordo com a classificação climática de Köppen, llha Solteira se caracteriza como Aw, tropical úmido, com inverno seco e ameno e verão quente e chuvoso (ROLIM et al. 2007). As amostras de água foram coletadas durante o período de estiagem (maio a outubro) e chuvoso (novembro a abril), com periodicidade mensal, entre os meses de maio de 2012 a abril de 2013, em dois pontos de amostragem (P1 e P2), totalizando doze campanhas (Figura 1).
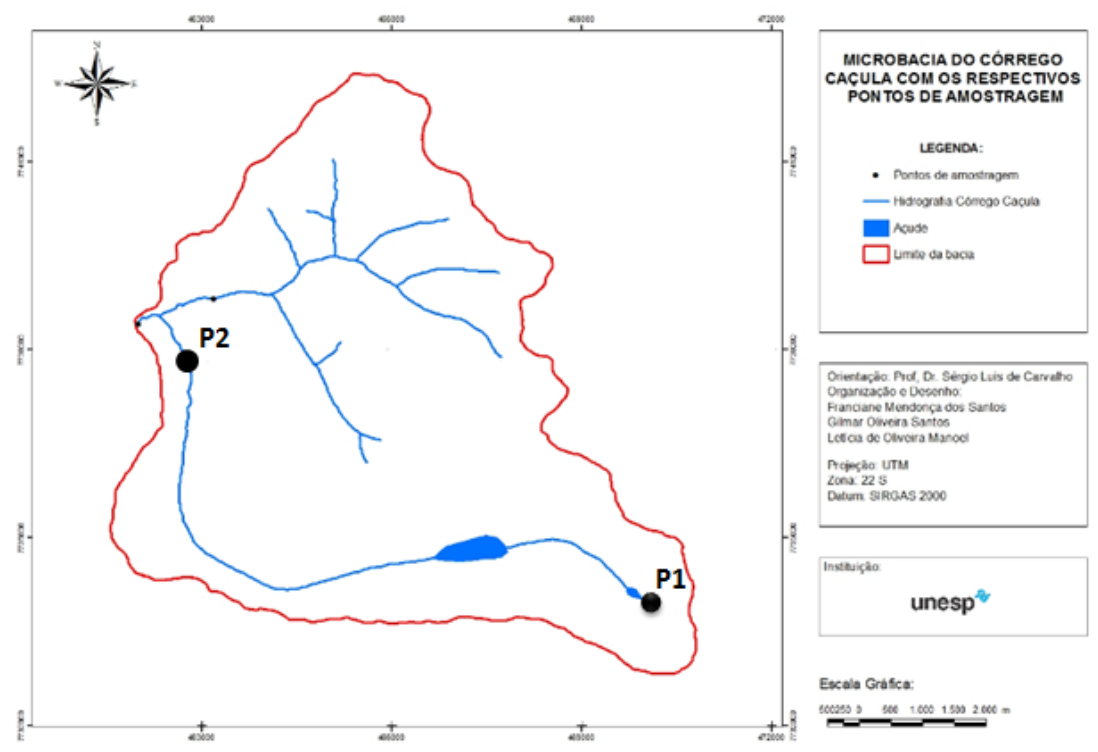

Figura 1. Mapa da microbacia do Córrego Caçula com os respectivos pontos de amostragem.

O Ponto 1 (Figura 2) consiste na nascente do Córrego das Lagoas, localizada nas

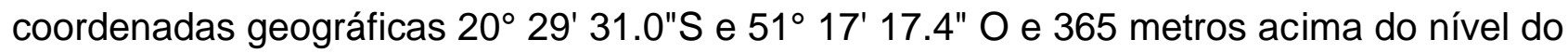
mar. Este local caracteriza-se pela ausência da área de preservação permanente (APP), e pelo leito raso e alargado, quase todo ocupado por espécies vegetais invasoras, como: Brachiaria sp. (capim) e Typha sp. (taboa). O Ponto 2 consiste na Foz do córrego das Lagoas, o local de monitoramento possui as coordenadas $20^{\circ} 27^{\prime} 05.3^{\prime \prime S}$ e $51^{\circ} 21^{\prime} 45.8^{\prime \prime} \mathrm{O}$ e 288 metros acima do nível do mar. Apresenta reduzidas áreas de preservação permanente e consequentemente proliferação da taboa (Thypa sp.) 

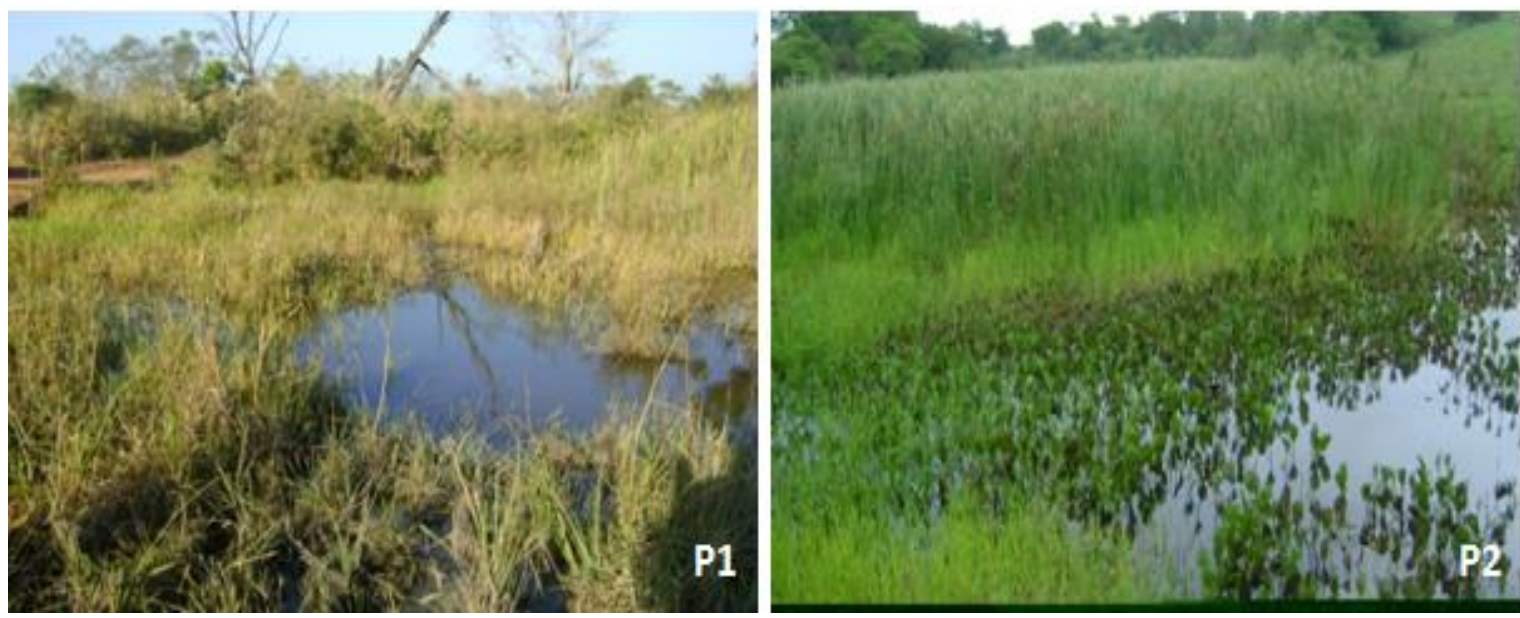

Figura 2. Imagens ilustrativas dos pontos amostrados para a análise de água da Nascente (P1) e Foz (P2) do Córrego das Lagoas, município de Ilha Solteira - SP.

\subsection{Metodologias de coleta de amostras}

As amostras de água foram coletadas em frasco de polietileno. No campo foi feito a medição da temperatura da água, utilizando termômetro portátil em horário das 09h00min às $11 \mathrm{~h} 00 \mathrm{~min}$.

As análises experimentais foram realizadas no laboratório de Saneamento do Departamento de Engenharia Civil da Faculdade de Engenharia de llha Solteira (UNESP), onde foram realizadas todas as análises em no máximo 24 horas após a coleta.

Os dados de precipitação pluviométrica foram obtidos pela Estação Agrometeorológica operada pela Área de Hidráulica e Irrigação da UNESP de llha Solteira, compreendendo a série histórica das precipitações (em milímetros) ocorridas nos meses de amostragem.

\subsection{Determinação dos Parâmetros Físico-Químicos e Biológicos}

No presente trabalho, foram feitas análises das condições físicas, químicas e biológicas, com base nos Métodos para as Análises de Águas Potáveis e Residuárias - 
Standard Methods for Examination of Water and Wastewater (APHA-AWWA-WPCF, 1998) para os seguintes parâmetros:

Parâmetros físicos: Turbidez (NTU) e Temperatura $\left({ }^{\circ} \mathrm{C}\right)$;

Parâmetros químicos: $\mathrm{pH}$, Nitrogênio Total $\left(\mathrm{mg} \mathrm{L}^{-1}\right)$, Fósforo Total $\left(\mathrm{mg} \mathrm{L}^{-1}\right)$, Demanda Bioquímica de Oxigênio DBO $\left(\mathrm{mg} \mathrm{L}^{-1}\right)$, Oxigênio Dissolvido OD $\left(\mathrm{mg} \mathrm{L}^{-1}\right)$, Sólidos Totais $\left(\mathrm{mg} \mathrm{L}^{-1}\right)$, e

Parâmetros biológicos: Coliforme Termo tolerante (NMP/100 ml).

A Tabela 1, apresenta a síntese da metodologia utilizada para a determinação de cada parâmetro analisado.

Tabela 1. Síntese das metodologias, equipamentos e precisão nas análises de qualidade de água.

\begin{tabular}{|c|c|c|c|c|}
\hline PARÂMETROS & $\begin{array}{c}\text { UNIDADE } \\
\text { DE MEDIDA }\end{array}$ & MÉTODOS & $\begin{array}{c}\text { PRECISÕE } \\
\mathbf{S}\end{array}$ & EQUIPAMENTOS \\
\hline Turbidez & NTU & Nefelométrico & 0,01 & $\begin{array}{c}\text { Turbidímetro/Hach/ } \\
2100 \mathrm{NA} v 1.2\end{array}$ \\
\hline Temperatura & ${ }^{\circ} \mathrm{C}$ & Eletrométrico & & Termômetro portátil \\
\hline $\mathrm{pH}$ & - & Eletrométrico & 0,01 & $\begin{array}{c}\text { pHmetro de } \\
\text { membrana/Hanna/ } \\
\text { HI8314 }\end{array}$ \\
\hline Fósforo Total & $\mathrm{mg} \mathrm{L}^{-1}$ & $\begin{array}{l}\text { Digestão por Ácido } \\
\text { Persulfato e } \\
\text { Espectrofotométrico }\end{array}$ & 0,01 & $\begin{array}{l}\text { Espectrofotômetro } \\
\text { Odyssey/ } \\
\text { Hach/DR-2500 }\end{array}$ \\
\hline Nitrogênio Total & $\mathrm{mg} \mathrm{L}^{-1}$ & $\begin{array}{l}\text { Digestão por Ácido } \\
\text { Persulfato e } \\
\text { Espectrofotométrico }\end{array}$ & 0,1 & $\begin{array}{c}\text { Espectrofotômetro } \\
\text { Odyssey/ } \\
\text { Hach/DR-2500 }\end{array}$ \\
\hline DBO & $\mathrm{mg} \mathrm{L}^{-1}$ & $\begin{array}{c}\text { Método das } \\
\text { Diluições, } \\
\text { Incubado a } 20^{\circ} \mathrm{C}, 5 \\
\text { dias }\end{array}$ & 0,1 & $\begin{array}{c}\text { Pipetas de } 2 \mathrm{ml} \text {, } \\
\text { garrafas de Van Dorn e } \\
\text { Titulador }\end{array}$ \\
\hline OD & $\mathrm{mg} \mathrm{L}^{-1}$ & $\begin{array}{l}\text { Método de Winkler } \\
\text { Modificado }\end{array}$ & 0,1 & Titulador \\
\hline Sólidos totais & $\mathrm{mg} \mathrm{L}^{-1}$ & Gravimétrico & 1,0 & $\begin{array}{c}\text { Cápsula de Porcelana } \\
\text { Disco de microfibra de } \\
\text { vidro/Sartorius } \\
\text { Balança eletrônica de } \\
\text { precisão de } 0,1 \mu \mathrm{gg} / \mathrm{Bel} \\
\text { Mark/ U210A } \\
\text { Estufa/Marconi/MA033/ } \\
\text { temp.120ㅇ } \\
\text { Dissecador/Pyrex/200m } \\
\mathrm{m}\end{array}$ \\
\hline
\end{tabular}




\begin{tabular}{ccccc} 
Coliformes fecais & $\begin{array}{c}\mathrm{NMP} / 100 \mathrm{ml} \\
\text { de } \\
\text { amostra }\end{array}$ & $\begin{array}{c}\text { Contagem de } \\
\text { bactérias }\end{array}$ & $\begin{array}{c}100 \mathrm{col} / 100 \\
\mathrm{ml}\end{array}$ & $\begin{array}{c}\text { Procedimento de } \\
\text { análise, Kit } \\
\text { microbiológico - } \\
\text { Sartorius. }\end{array}$ \\
\hline
\end{tabular}

\section{RESULTADOS E DISCUSSÃO}

\subsection{Variáveis Avaliadas}

Para verificar a qualidade da água do córrego das Lagoas foram analisadas as seguintes variáveis $(\mathrm{pH}$, turbidez, fósforo total, $\mathrm{DBO}$, nitrogênio total, oxigênio dissolvido, sólidos totais, coliformes fecais e temperatura). Os resultados das análises de água nos dois pontos de amostragens, nos períodos de seca e de chuva, estão apresentados na Tabela 2.

Tabela 2. Resultado das análises de água nos pontos de amostragens do Córrego das Lagoas nos períodos de seca e de chuva.

\begin{tabular}{|c|c|c|c|c|c|c|c|c|}
\hline \multirow{2}{*}{ Parâmetro } & \multirow{2}{*}{ Estação } & \multicolumn{3}{|c|}{ Período Seco } & \multicolumn{3}{|c|}{ Período Chuvoso } & \multirow{2}{*}{ CONAMA 357/05 } \\
\hline & & $\operatorname{Min}^{1}$ & $\operatorname{Max}^{2}$ & méd $^{3}$ & $\operatorname{Min}^{1}$ & $\operatorname{Max}^{2}$ & méd $^{3}$ & \\
\hline \multirow{2}{*}{ Temperatura da água $\left({ }^{\circ} \mathrm{C}\right)$} & 1 & 19 & 25 & 21 & 20 & 23 & 21,6 & \multirow[b]{2}{*}{-} \\
\hline & 2 & 21 & 23 & 22,3 & 21 & 28 & 23,6 & \\
\hline \multirow{2}{*}{$\mathrm{pH}$} & 1 & 5,65 & 6,32 & 6,04 & 5,37 & 7,24 & 5,96 & \multirow{2}{*}{6,0 a 9,0} \\
\hline & 2 & 6,98 & 7,57 & 7,16 & 6,63 & 7,67 & 6,92 & \\
\hline \multirow{2}{*}{$O D\left(\mathrm{mg} \mathrm{L}^{-1}\right)$} & 1 & 0,9 & 4,78 & 3,37 & 0 & 8,95 & 4,46 & \multirow{2}{*}{$>5,0$} \\
\hline & 2 & 2,36 & 10,91 & 8,12 & 8,56 & 11,85 & 9,5 & \\
\hline \multirow{2}{*}{$\mathrm{DBO}\left(\mathrm{mg} \mathrm{L}^{-1}\right)$} & 1 & 2 & 5 & 3,41 & 1 & 6 & 2,5 & \multirow{2}{*}{$\leq 5,0$} \\
\hline & 2 & 0 & 4 & 1,87 & 0 & 1 & 0,5 & \\
\hline \multirow{2}{*}{ Turbidez (NTU) } & 1 & 3,45 & 6,19 & 4,9 & 16,7 & 183 & 68,2 & \multirow{2}{*}{$\leq 100,0$} \\
\hline & 2 & 4,34 & 11,7 & 6,6 & 8,8 & 31,4 & 15,8 & \\
\hline \multirow{2}{*}{$\mathrm{ST}\left(\mathrm{mg} \mathrm{L}^{-1}\right)$} & 1 & 56 & 130 & 99,3 & 100 & 740 & 366,6 & \multirow[t]{2}{*}{500} \\
\hline & 2 & 100 & 150 & 123,3 & 100 & 150 & 123,3 & \\
\hline \multirow{2}{*}{ Fósforo total $\left(\mathrm{mg} \mathrm{L}^{-1}\right)$} & 1 & 0,07 & 1,2 & 0,8 & 0,35 & 3 & 1,4 & \multirow[t]{2}{*}{$0,050 \mathrm{mg} \mathrm{L}^{-1}$} \\
\hline & 2 & 0,47 & 2,09 & 1,05 & 0,54 & 3,89 & 1,86 & \\
\hline \multirow{2}{*}{ Nitrogênio total ( $\mathrm{mg} \mathrm{L}^{-1}$ ) } & 1 & 0,3 & 3 & 1,83 & 0,2 & 10,9 & 2,61 & \multirow{2}{*}{-} \\
\hline & 2 & 0,7 & 1,5 & 1,05 & 0,1 & 1,9 & 0,68 & \\
\hline \multirow{2}{*}{ Coliformes fecais (NMP/100ml) } & 1 & 0 & 500 & 150 & 100 & 300 & 166,6 & \multirow{2}{*}{$1000 / 100 \mathrm{ml}$} \\
\hline & 2 & 0 & 100 & 33,3 & 0 & 600 & 200 & \\
\hline
\end{tabular}

*Valores para águas doces de classe 2- Resolução CONAMA 357/05. 


\subsubsection{Temperatura da água}

A temperatura tem grande importância como parâmetro de qualidade, pois as elevações da temperatura aumentam as taxas das reações químicas e biológicas, diminuem a solubilidade dos gases e aumentam a taxa de transferência dos mesmos, o que pode gerar mau cheiro, no caso da liberação de gases com odores desagradáveis.

No período seco, a temperatura da água no córrego das Lagoas variou de $19^{\circ} \mathrm{C}$ a $25^{\circ} \mathrm{C}$, enquanto que no período chuvoso, variou de $20^{\circ} \mathrm{C}$ a $28^{\circ} \mathrm{C}$. Esses dados expressam variação de acordo com a temperatura do ar, com menores valores na seca $\left(19^{\circ} \mathrm{C}\right)$ no mês de maio e maiores valores na chuva, em janeiro $\left(28^{\circ} \mathrm{C}\right)$.

A Figura 3 ilustra os resultados obtidos nas análises, onde no Ponto 1 a temperatura mínima da água foi de $19{ }^{\circ} \mathrm{C}$ e a máxima de $25 \stackrel{\circ}{\circ} \mathrm{C}$, com mediana de $21^{\circ} \mathrm{C}$ e no Ponto 2 registrou-se a mínima de $21^{\circ} \mathrm{C}$ e a máxima de $28^{\circ} \mathrm{C}$ e a mediana de $23^{\circ} \mathrm{C}$,

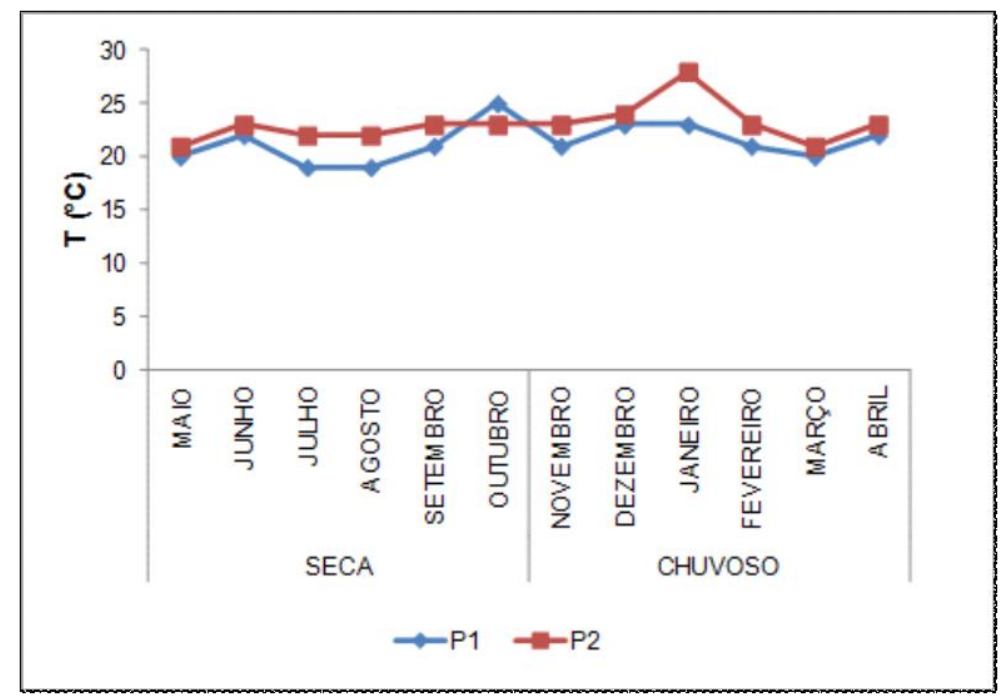

com menores valores no Ponto 1.

Figura 3. Variação temporal da temperatura nos pontos 1 e 2 no período de maio/2012 a abril/2013, localizados no Córrego das Lagoas, município de Ilha Solteira - SP.

De maneira geral a temperatura da água no Córrego das Lagoas apresentou valores baixos quando comparados com outros corpos d'água. Barros e Souza (2012) ao realizar um monitoramento da água no Córrego André, encontrou variação de temperatura 
de $27^{\circ} \mathrm{C}$ a $30^{\circ} \mathrm{C}$ no período seco, enquanto que, no período chuvoso, variou de 29,3 a $30^{\circ} \mathrm{C}$.

\subsubsection{Potencial hidrogeniônico (pH)}

A variação de $\mathrm{pH}$, tanto no período de seca quanto no período de chuvas estiveram com valores mostrando tendência a valores entre neutros e ácidos, isto é, entre 5,37 e 7,67 (Figura 4). Os valores de pH no P1, variaram de 5,37 a 7,24, com média igual a 6,0 e no Ponto 2, o pH mínimo registrado foi de 6,63 e o máximo de 7,67, com média 7,04 , revelando baixa variabilidade espacial e sazonal, e esteve dentro dos padrões recomendados, entre 6 e 9, pela Resolução CONAMA n. ${ }^{\circ} 357 / 2005$, exceto nas amostras coletadas no ponto amostral 1 , em que ocorreram soluções ácidas, com valor médio igual a 6,0 .

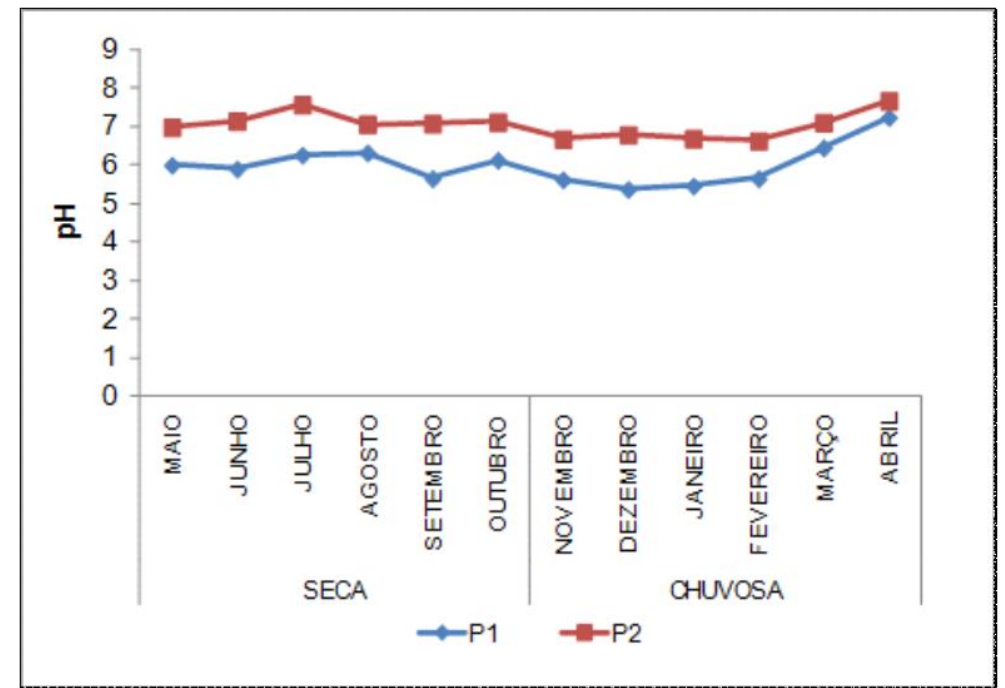

Figura 4. Variação temporal do pH nos pontos 1 e 2 no período de maio/2012 a abril/2013, localizados no Córrego das Lagoas, município de llha Solteira - SP.

\subsubsection{Oxigênio dissolvido (OD)}


O oxigênio dissolvido é indispensável à sobrevivência dos organismos aeróbios. As concentrações médias de oxigênio dissolvido na massa líquida nas áreas estudadas variaram de 0 a 11,85 $\mathrm{mg} \mathrm{L}^{-1}$ no período chuvoso, e de 0,9 a $8,12 \mathrm{mg} \mathrm{L}^{-1}$, no período seco. Os teores de oxigênio dissolvido, analisados nos pontos amostrais, apresentaram variações de 0 a $8,95 \mathrm{mg} \mathrm{L}^{-1}$, com mediana de $3,91 \mathrm{mg} \mathrm{L}^{-1}$ no Ponto 1 e 2,36 a 11,85 mg $\mathrm{L}^{-1}$, com mediana de $8,81 \mathrm{mg} \mathrm{L}^{-1}$ no Ponto 2 (Figura 4). A nascente do Córrego das Lagoas (P1) não apresentou concordância com os valores de referência do CONAMAResolução 357/2005, para águas de classe $2\left(>5,00 \mathrm{mg} \mathrm{L}^{-1}\right)$, exceto no meses de dezembro e janeiro, com 8,95 e $6,33 \mathrm{mg} \mathrm{L}^{-1}$, respectivamente.

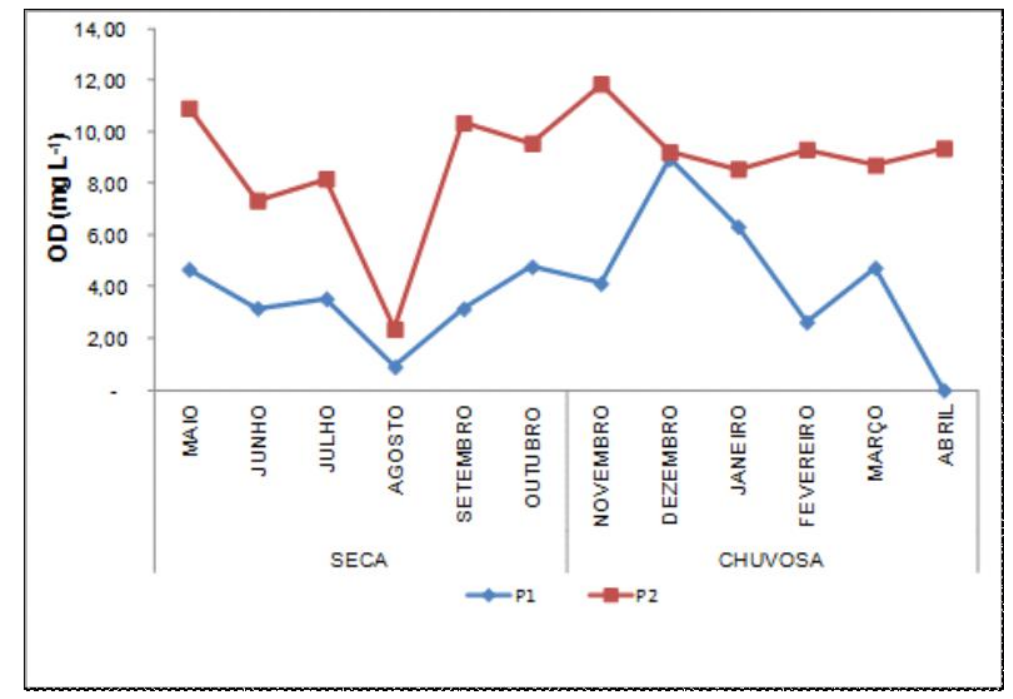

Figura 5. Variação temporal do Oxigênio Dissolvido (OD) nos pontos 1 e 2 no período de maio/2012 a abril/2013, localizados no Córrego das Lagoas, município de llha Solteira - SP.

\subsubsection{Demanda bioquímica de oxigênio (DBO)}

Os teores de DBO nos pontos estudados apresentaram oscilações entre máximos e mínimos na ordem de 0 a $5 \mathrm{mg} \mathrm{L}^{-1}$ na seca, e 0 a $6 \mathrm{mg} \mathrm{L}^{-1}$ na chuva. Os valores de DBO nos períodos de seca e chuva estiveram de acordo com os padrões de referência da Resolução CONAMA 357/05, que é de até $5,00 \mathrm{mg} \mathrm{L}^{-1}$, para a classe 2, exceto no mês de novembro no P1, mostrando que não houve influência sazonal. 
Os teores mínimo e máximo de DBO registrados no Ponto 1 oscilaram de 1 a $6 \mathrm{mg}$ $\mathrm{L}^{-1}$, com mediana de $3 \mathrm{mg} \mathrm{L}^{-1}$ e no Ponto 2 , a mínima de $0 \mathrm{mg} \mathrm{L}^{-1}$ e o valor máximo a $4 \mathrm{mg}$

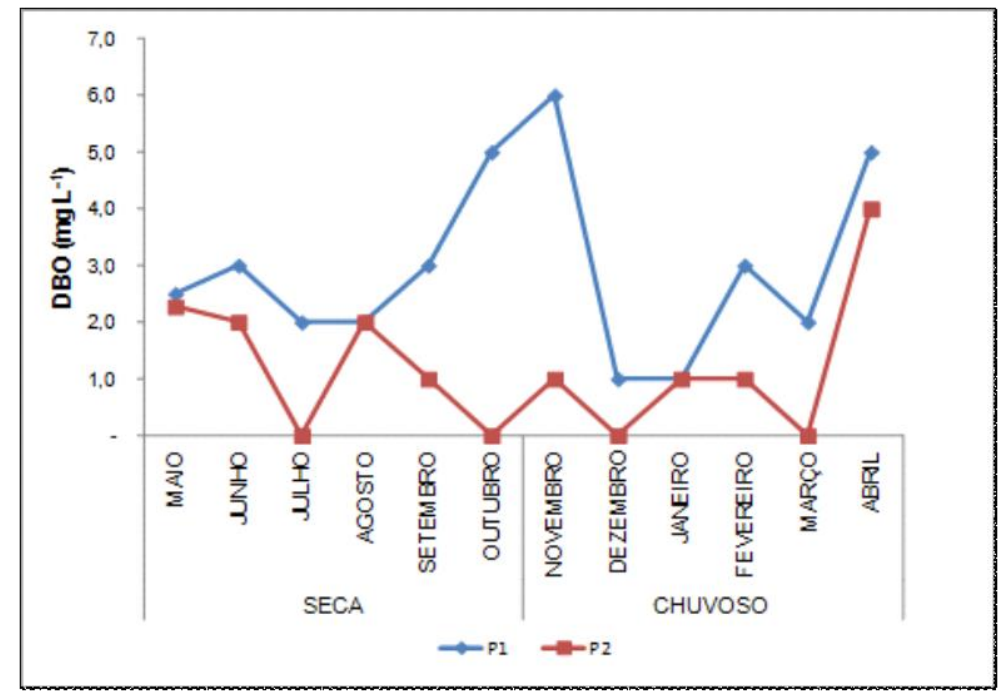

$\mathrm{L}^{-1}$, com mediana de $1 \mathrm{mg} \mathrm{L}^{-1}$ (Figura 6).

Figura 6. Variação temporal da Demanda bioquímica de oxigênio (DBO) nos pontos 1 e 2 no período de maio/2012 a abril/2013, localizados no Córrego das Lagoas, município de llha Solteira - SP.

\subsubsection{Turbidez}

Na Figura 7, podem ser observadas as variações sazonais ao longo do período de coletas, com valores mínimos registrados no período de estiagens (entre os meses de maio a outubro), e máximos no período das chuvas (novembro à abril).

Os valores da turbidez no Ponto 1, estiveram entre 3,45 e 183 NTU e a mediana de 36,5 NTU e no Ponto 2 os valores mínimo e máximo foram de 4,34 e 31,4 NTU, com uma mediana de 11,22 NTU.

A principal consequência da alteração da turbidez num corpo d'água é a redução da penetração de luz solar, prejudicando a oxigenação do meio. Nos pontos analisados, a turbidez permaneceu dentro do valor máximo permitido pela Resolução 357/05 do CONAMA, que é de 100 NTU, na maior parte do tempo analisado, exceto no Ponto 1, com 183 NTU no mês de janeiro. 
Constata-se que no período chuvoso as águas nesses pontos apresentaram

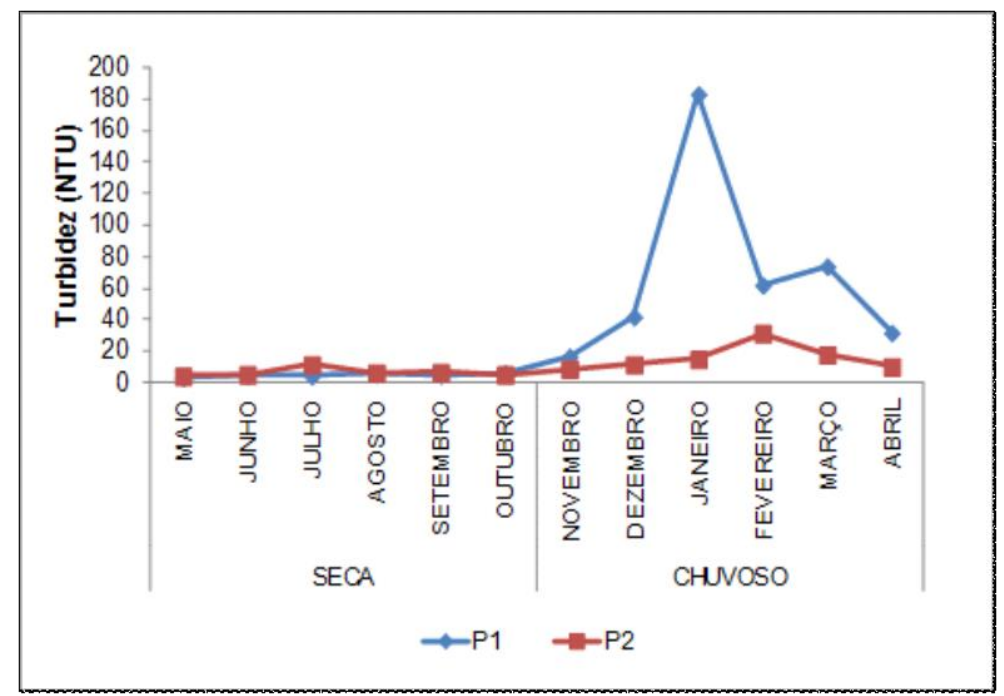

maiores quantidades de sólidos suspensos resultando em maior turbidez.

Figura 7. Variação temporal da Turbidez nos pontos 1 e 2 no período de maio/2012 a abril/2013, localizados no Córrego das Lagoas, município de llha Solteira - SP.

\subsubsection{Sólidos totais}

A variação de concentração dos sólidos totais pode ser observada na Figura 8, com maiores valores nos períodos de chuva e menores na seca. As erosões próximas ao leito do córrego e o escoamento superficial devido ao uso do solo, influenciaram nos picos de concentrações ocorridos nos períodos de chuva. Constata-se, que no P2 não houve variações significativas durante o período de coleta, com valores mínimo e máximo de 100 e $150 \mathrm{mg} \mathrm{L}^{-1}$, com mediana de $123,3 \mathrm{mg} \mathrm{L}^{-1}$ entretanto, no Ponto 1 os valores variaram entre 56 a $740 \mathrm{mg} \mathrm{L}^{-1}$, com mediana de $233 \mathrm{mg} \mathrm{L}^{-1}$. Estes valores foram inferiores ao limite estabelecido (500 mg.L-1) pela Resolução Conama (Brasil) no 357/2005 para as águas de classe 2, de água doce, exceto no mês de janeiro, com 740 $\mathrm{mg} \mathrm{L}^{-1}$. 


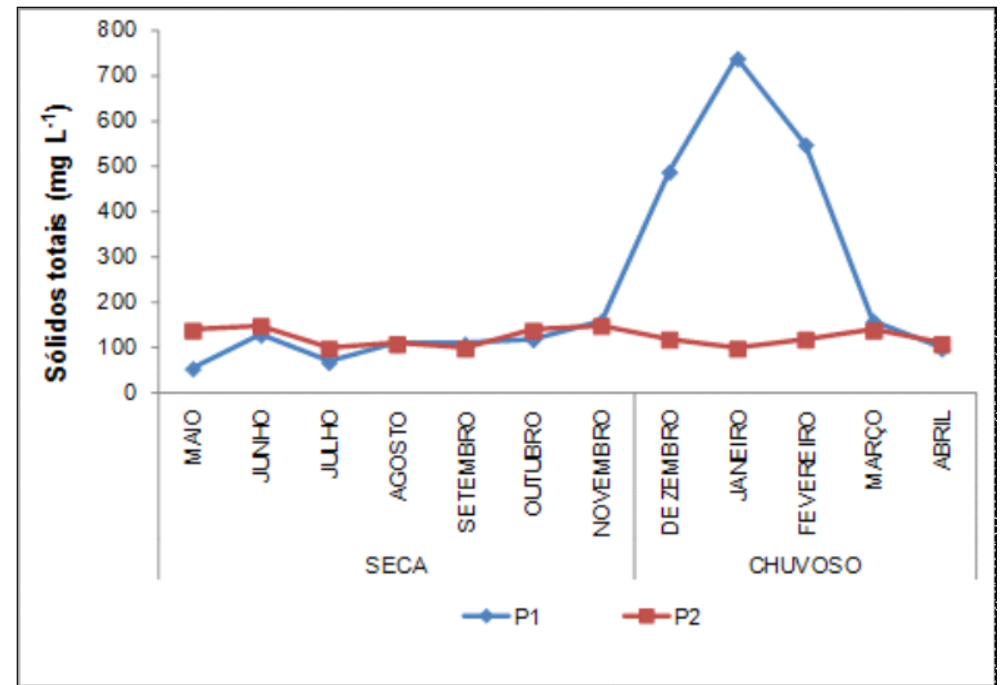

Figura 8. Variação temporal dos Sólidos totais nos pontos 1 e 2 no período de maio/2012 a abril/2013, localizados no Córrego das Lagoas, município de llha Solteira - SP.

A menor quantidade de oxigênio dissolvido e a elevação das concentrações de sólidos, turbidez e da demanda bioquímica de oxigênio no período chuvoso no Ponto1, deve-se ao fato deste ponto estar mais suscetível ao carreamento do solo e do transporte de sedimentos na bacia, devido a más condições de preservação, principalmente pela ausência de matas ciliares na nascente.

\subsubsection{Fósforo total}

O fósforo é um nutriente essencial para todas as formas de vida, pois é parte das estruturas celulares. O parâmetro Fósforo Total, teve valores de concentração relativamente altos, com variação de 0,07 a $3 \mathrm{mg} \mathrm{L}^{-1}$ e a mediana de $1,10 \mathrm{mg} \mathrm{L}^{-1}$ no Ponto 1 e de 0,47 a $3,89 \mathrm{mg} \mathrm{L}^{-1}$, com mediana de $1,46 \mathrm{mg} \mathrm{L}^{-1}$ no Ponto 2 (Figura 9). Nos dois pontos de amostragem, ultrapassou o valor de referência para a classe 2, que é de até 0,0500 $\mathrm{mg} \mathrm{L}^{-1}$ (Resolução CONAMA 357/05). Segundo Freitas (2000), as águas drenadas em áreas agrícolas e urbanas podem provocar a presença excessiva de fósforo em águas naturais entre outras fontes antrópicas. 


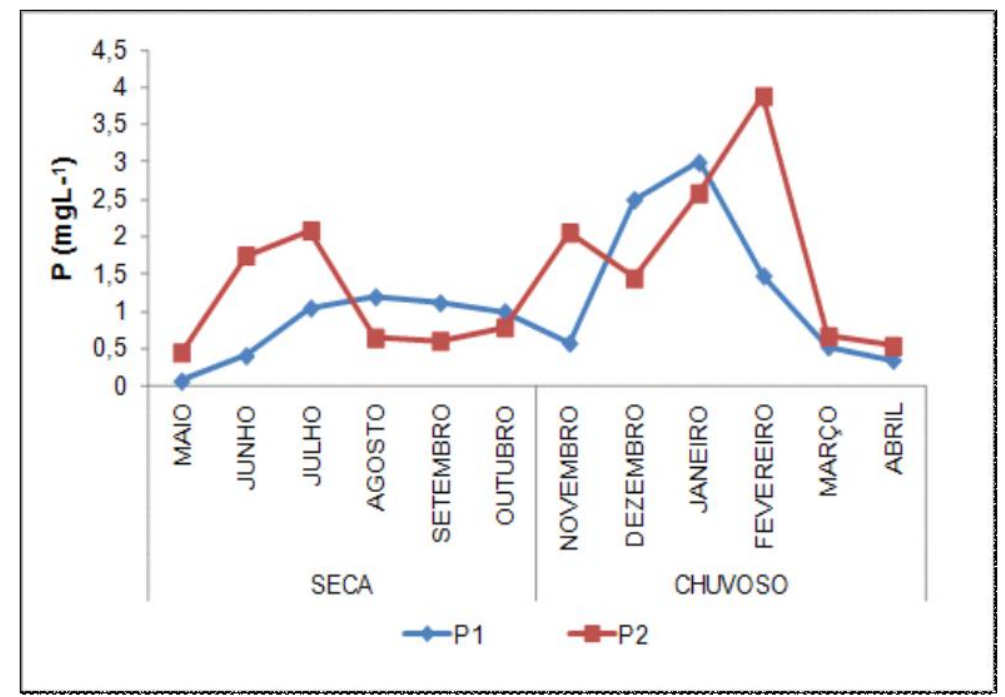

Figura 9. Variação temporal do Fósforo total $(P)$ nos pontos 1 e 2 no período de maio/2012 a abril/2013, localizados no Córrego das Lagoas, município de llha Solteira - SP.

Estas altas concentrações foram, provavelmente, decorrentes da descarga das águas drenadas em áreas agrícolas, devido à falta de práticas de conservação do solo que são eficientes na retenção das águas pluviais e controle de erosão, podendo contribuir para a proliferação de algas e para a aceleração indesejável do processo de eutrofização.

\subsubsection{Nitrogênio total}

As concentrações de Nitrogênio Total ao longo da série analisada nos pontos de amostragem, apontam que o Nitrogênio teve elevações nos valores principalmente no período chuvoso, com valores de concentrações variando de 0,1 a $10,9 \mathrm{mg} \mathrm{L}^{-1}$ e para o período de seca variou de 0,3 a $3 \mathrm{mg} \mathrm{L}^{-1}$. Dentre as fontes de Nitrogênio no Córrego das Lagoas, está a dispersão difusa de fertilizantes nitrogenados utilizados nas lavouras. Ríos Villamizar et al. (2011) também verificaram que no rio Purus, a variável nitrogênio total apresentou os maiores valores no período da cheia. 
Na Figura 10 observa-se a variação de nitrogênio total nos dois pontos em estudo, ao longo das análises, as concentrações mínima e máxima no Ponto 1 foram de 0,2 a $10,9 \mathrm{mg} \mathrm{L}^{-1}$ e a mediana de $2,2 \mathrm{mg} \mathrm{L}^{-1}$ e no Ponto 2 os valores oscilaram entre 0,1 e 1,9 $\mathrm{mg} \mathrm{L}^{-1}$, com mediana de $0,86 \mathrm{mg} \mathrm{L}^{-1}$.

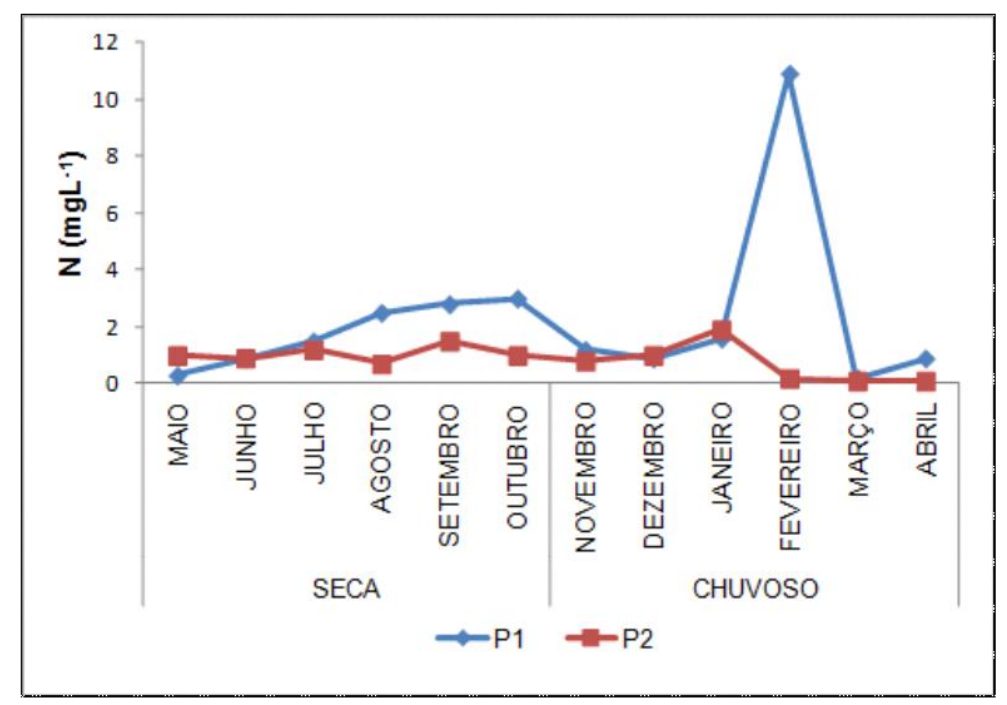

Figura 10. Variação temporal do Nitrogênio total (N) nos pontos 1 e 2 no período de maio/2012 a abril/2013, localizados no Córrego das Lagoas, município de llha Solteira - SP.

Em relação ao nitrogênio, maiores teores em águas menos oxigenadas indicam maior presença de nitrito e nitrogênio amoniacal visto que o nitrato ocorre mais em águas oxigenadas.

\subsubsection{Coliformes fecais}

A quantidade de Coliformes Fecais sofre variação apresentando picos de variação de acordo com o período sazonal onde as maiores concentrações foram registradas no período de chuva. Na Resolução 357/05 para os coliformes fecais nas águas de classe 2 determina que o Número Mais Provável (NMP) é de 1000/100mL. A Figura 11 mostra que os valores obtidos nas estações de coleta no período chuvoso e de seca, estão de acordo com o limite permitido pelo CONAMA, onde a maior concentração, registrada no Ponto 2, deve-se à contribuição de fezes de animais (vacas, cavalos, porcos, galinhas, entre outros) e fezes humanas das chácaras localizadas ao longo das margens do córrego. 


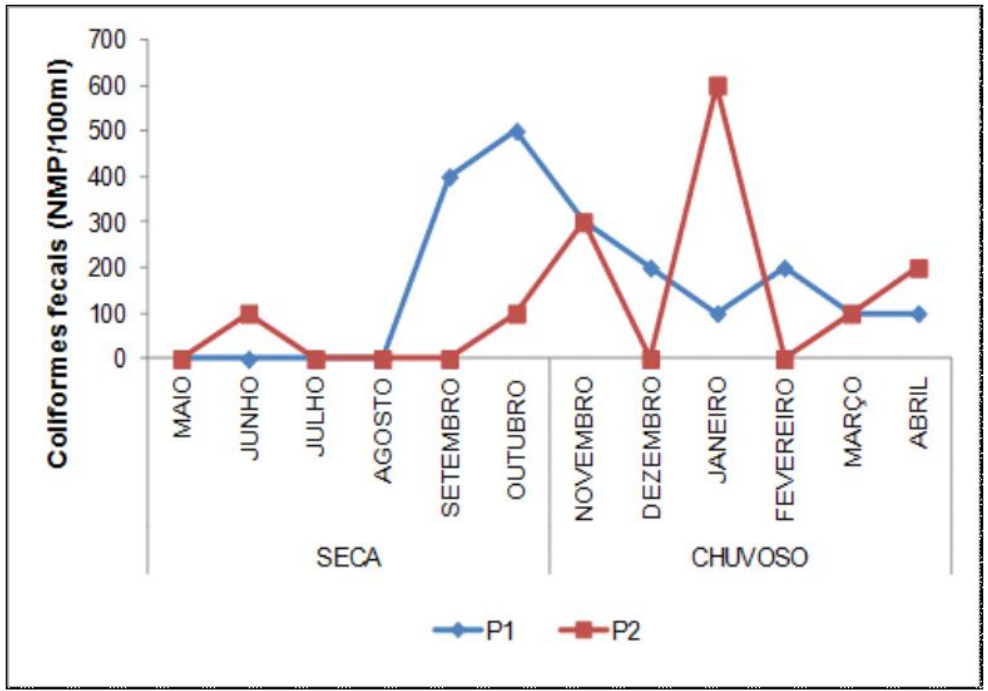

Figura 11. Variação temporal dos Coliformes fecais nos pontos 1 e 2 no período de maio/2012 a abril/2013, localizados no Córrego das Lagoas, município de llha Solteira - SP.

\section{CONCLUSÃO}

Os resultados das análises da água mostraram que o Córrego das Lagoas apresenta alterações ligadas a fatores temporais e espaciais, com perda progressiva da qualidade das águas no período chuvoso, e diferenças na qualidade nos trechos referente à nascente e na foz.

Os sólidos totais apresentaram maiores valores no período chuvoso e a turbidez seguiu o mesmo comportamento, o que era esperado devido ao carreamento do solo e ao transporte de sedimentos na bacia, com aumento da quantidade de material suspenso, havendo indícios de carreamento de fósforo, que se fez presente em altas concentrações, excedendo os limites estabelecidos (Resolução CONAMA n 357/05) nos dois períodos de coleta, tanto chuvosos como seco.

Os impactos na qualidade da água foram predominantes no Ponto 1, que consiste na nascente do Córrego das Lagoas. Vale salientar a importância da proteção desse manancial, incluindo o manejo de terras em nível e a recuperação da vegetação no seu entorno visando à preservação e melhoria da quantidade e qualidade da água. 


\section{REFERÊNCIAS}

APHA, AWWA, WPCF. Standard methods for the examination of water and wastewater. $20^{\text {th }}$ ed. Washington, DC: APHA, 1998.

BARROS, R. V. G.; SOUZA, C. A. Qualidade do recurso hídrico do Córrego André, Mirassol D. Revista Brasileira de Ciências Ambientais, USP, v. 24, p.1-16, fev. 2012. Disponível em: <http://www.rbciamb.com.br/images/online/Materia_1_artigos312.pdf>. Acesso em: 04 ago. 2013.

BUENO, L.F.; GALBIATTI, J.A.; BORGES, M.J. Monitoramento de variáveis de qualidade de água no horto Ouro Verde - Conchal - SP. Engenharia Agrícola, Jaboticabal, v.25, n.3, p.742-748, 2005.

CONSELHO NACIONAL DO MEIO AMBIENTE - CONAMA. 2005. Resolução Conama $n^{\circ}$ 357. Disponível em:< www.mma.conama.gov.br/conama> Acesso em 02/07/2013.

FREITAS, A. J. Gestão de recursos hídricos. In: SILVA, D. D.; PRUSKI, F. F. (Orgs.). Gestão de recursos hídricos: aspectos legais, econômicos, administrativos e legais. Brasília: Secretaria de Recursos Hídricos; Viçosa, MG: Universidade Federal de Viçosa; Porto Alegre: Associação Brasileira de Recursos Hídricos, 2000. 659 p.

RÍOS-VILLAMIZAR, E. A.; JUNIOR, A. F. M.; WAICHMAN, A. V. Caracterização físicoquímica das águas e desmatamento na bacia do rio Purus, Amazônia Brasileira Ocidental. Rev. Geogr. Acadêmica, Goiás, v. 5, n.2, p.54-65, dez. 2011. Disponível em: $<$ http://rga.ggf.br/index.php?journal=rga\&page=article\&op=view\&path\%5B\%5D $=177 \&$ path $\% 5 \mathrm{~B} \% 5$ $\underline{D=0}$ >. Acesso em: 04 ago. 2013. 
ROLIM, G.S; CAMARGO, M.B.P; LANIA, D. G. MORAES, J.F.L. Classificação climática de Köppen e de Thornthwaite e sua aplicabilidade na determinação de zonas agroclimáticas para o estado de são Paulo. Bragantia [online]. 2007, vol.66, n.4, pp. 711-720. ISSN 1678-4499.

STRIEDER, M.N.; RONCHI, L.H.; STENERT, C.; SCHERER, R.T.; NEISS, U.G. Medidas biológicas e índices de qualidade da água de uma microbacia com poluição urbana e de curtumes no Sul do Brasil. Acta Biológica Leopoldensia, Porto Alegre, v.28, n.1, p.1724, 2006. 